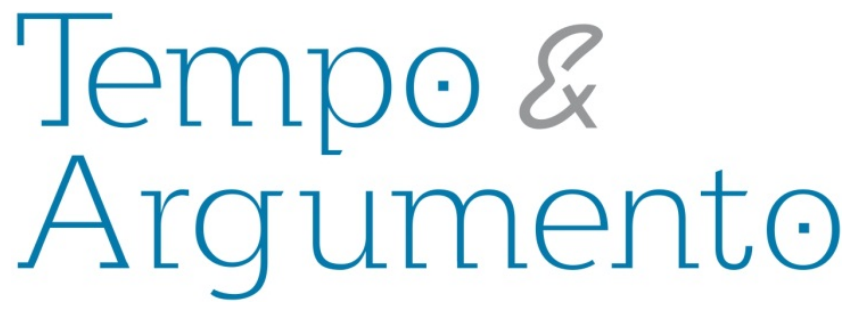

\title{
Questões que atravessam os tempos: os discursos e a construção do corpo feminino
}

\section{Resenha da obra:}

COLLING, Ana Maria. Tempos diferentes, discursos iguais: a construção do corpo feminino na história. Dourados, MS: Ed. UFGD, 2014.114 p.

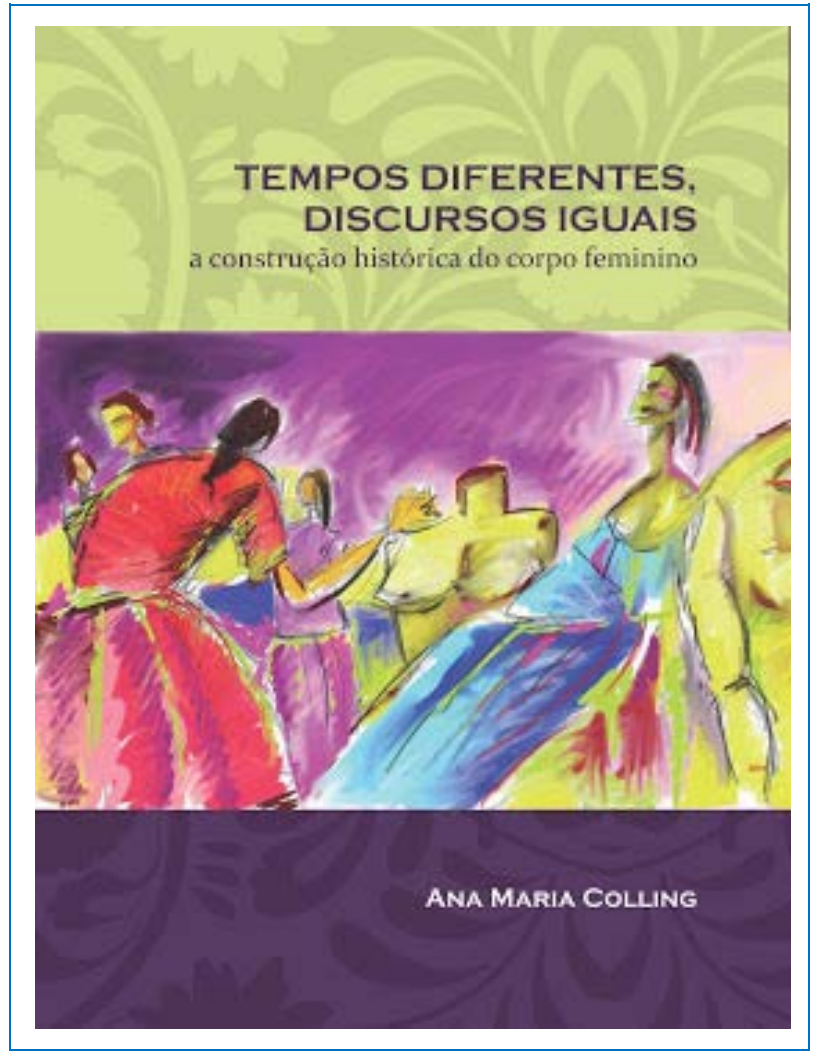

\section{Autora da resenha}

Nicolle Taner de Lima

Mestranda no Programa de Pós-Graduação em História da Universidade do Estado de Santa

Catarina. Bolsista CAPES.

Brasil

nicolletaner@gmail.com

\section{Para citar esta resenha:}

LIMA, Nicolle Taner de. Questões que atravessam os tempos: os discursos e a construção do corpo feminino. Revista Tempo e Argumento, Florianópolis, v. 8, n. 18, p. 451 - 456. maio/abr. 2016. 
Alguns discursos atravessam os tempos. Podem mudar um pouco seus trejeitos, assumir uma nova roupagem, modificar seus termos, mas ainda impactam a vida das pessoas, seus valores, suas práticas cotidianas. "Tempos diferentes, discursos iguais: a construção do corpo feminino na história" trata desses discursos e nos leva a refletir sobre estas permanências, sobre a historiografia, acerca dos corpos femininos - nossos corpos - na História.

Em pouco mais de cem páginas, introdução e dois capítulos, poucas notas de rodapé e um texto leve e forte para ser lido em uma tarde, Ana Maria Colling ${ }^{1}$ demonstra que o corpo feminino não é apenas uma construção histórica, é uma confluência dos discursos religioso, médico, psiquiátrico, filosófico, pedagógico, psicológico, jurídico que, juntos, constroem o que é o feminino.

A autora inicia seu texto discutindo o silenciamento das mulheres na História, o fazer historiográfico como algo escrito por homens, sobre homens, para ser lido por homens: o "nós" do discurso universal é sempre masculino. Enfatiza, pois, a importância de se analisar a história sob a perspectiva de gênero e afirma que esta categoria pode nos ajudar a repensar a centralidade do discurso, reconhecendo o androcentrismo da história e questionando os modelos existentes.

Não só a história marginalizou durante muito tempo as mulheres como, junto a outras ciências, se entrelaçou nas tramas dos discursos que “(...) receitam o que é ser homem, o que é ser mulher, e os papéis sociais designados a ambos: descreve como se fazem as mulheres em determinada cultura; como se faz um corpo sexuado feminino" ( $p$. 17).

Pensar a construção deste corpo feminino através das representações das mulheres que colaboraram para se estabelecer o pensamento simbólico que distingue os

\footnotetext{
1 Ana Maria Colling é graduada em Estudos Sociais (1978) e Geografia pela UNIJUI (1980), possui Especialização em História da América Latina pela UFRGS (1982), Mestrado em História do Brasil pela UFRGS (1994) e Doutorado em História pela PUCRS (2000), com estágio na Universidade de Coimbra, Portugal. Atualmente, é professora do Programa de Pós-Graduação em História da Universidade Federal da Grande Dourados (UFGD). Grande autora e pesquisadora, é reconhecida no campo de estudos de gênero por seus trabalhos que versam sobre mulheres e ditadura militar no Brasil, a construção histórica do corpo feminino e masculino e acerca das relações de poder e gênero na História, além de pensar as contribuições de Michel Foucault para o campo historiográfico.
} 
sexos, definindo os embasamentos teóricos do livro é o tema do primeiro capítulo intitulado "O lastro cultural do feminino". Recorrendo as/aos autoras/es Linda Hutcheon, Guacira Lopes Louro, Joan Scott e Carole Paterman, Michel Foucault e Jaques Derrida, Colling faz uma defesa da História enquanto construção e da ideia de gênero enquanto diferença de sexos não ditada pela natureza, mas sim pela cultura e pela história.

No segundo tópico desse capítulo, “Michel Foucault, o discurso e as mulheres”, a autora elenca diversas contribuições do pensamento foucaultiano às teorias feministas. Entendendo o discurso como prática social, permeado pelas relações de poder, instalado nas práticas cotidianas, aparatos jurídicos, gestos e costumes, é possível se criticar essa produção discursiva, desnaturalizá-la, problematizá-la, enfim, descontruí-la. Para a autora, a crítica de Foucault ao universalismo e ao essencialismo ofereceu embasamento teórico para que se descontruam práticas, palavras e coisas...

“Tempos diferentes, discursos iguais" é o título do segundo capítulo. Nele, a autora demonstra que a "natureza feminina", apesar de muitas vezes ser tratada como uma evidência dada, também foi forjada a partir de discursos que relacionavam as mulheres com a irracionalidade, a indiscrição, a histeria, a perversão, ao passo que este forjar também nos associou à fragilidade, moralidade, docilidade, intuição, sensibilidade. Seríamos muito indisciplinadas e irracionais demais, o que nos tornaria incapazes para governar, mas também muito frágeis, moral e emocionalmente; precisaríamos, portanto, por natureza, de sujeição.

A autora questiona essa "natureza feminina" lançando mão de diversos autores que contribuíram para a construção desse discurso e que legitimaram todo tipo de imposição de subordinação às mulheres. Inicia com o discurso filosófico, primeiramente com Platão e sua tese de que as mulheres não deveriam ter o mesmo estatuto dos homens, visto que pariam pessoas, e não ideias (p. 50); depois, Hipócrates e a hierarquização dos corpos a partir da geração, do homem como produtor e da mulher como reprodutora, ele como semente e ela como campo (p. 53); Aristóteles e a menoridade e debilidade das mulheres, visto que a natureza distinguia quem manda e que obedece (p. 55); passa para Jean-Jaques Rousseau e suas ideias sobre a educação 
pudica e moral que as mulheres precisariam receber (p. 61); e finaliza com Immanuel Kant, para quem nós, mulheres, seríamos memoráveis apenas pela beleza (p. 62).

O catolicismo e o protestantismo, os textos bíblicos e de seus representantes norteiam a discussão do tópico "Discurso Religioso". A partir de uma discussão bibliográfica que põe em diálogo Padre Antonio Vieira, Calvino e Lutero, Tomás de Aquino e os papas João Paulo II e Bento XVI, a autora reflete sobre as ambiguidades com que estes discursos tratam as mulheres: a condenação bíblica do pecado, a censura da luxúria, a condenação à fogueira em oposição ao ideal mariano de bondade, ternura, maternidade.

Para "Discurso Médico", a autora recorre a autores de diversas temporalidades, dos gregos ao Brasil Colônia, que utilizavam seus conhecimentos médicos através de experiências com mulheres, para legitimar seu papel na sociedade - o que compete à geração e criação dos filhos, à inferioridade e à sujeição. A curiosidade pelo útero e a aversão à menstruação também possuem espaço nessa discussão, bem como no tópico seguinte, que aborda os discursos psiquiátrico e psicanalítico.

Retomando textos produzidos por médicos a partir do século XVIII sobre a histeria, maternidade e sexo, além dos textos freudianos e sua descrição do feminino como passivo, atrofiado e invejoso do falo, Colling discute a histerização e a normatização do corpo feminino.

Conclui seu livro recuperando algumas ideias articuladas nos capítulos, reafirmando o caráter transgeográfico e transcultural da subordinação das mulheres, que se manteve - e ainda se mantém, mesmo que com outras vestes - através de discursos das mais variadas ciências e religiões. Incita que se escreva uma história que reconheça o processo histórico de exclusão de sujeitos e ao fim, questiona: o que se fará da história para transformá-la e superar a desqualificação do feminino?

Minhas críticas ao livro são escassas, porém há a necessidade de mencioná-las. Uma relação maior entre as permanências e rupturas desses discursos poderia ser interessante para verificarmos esses "discursos iguais" aos quais a autora se refere. Outra questão a se problematizar é a sentença “(...) Foucault libertou as mulheres da sua 
natureza, permitindo que pudessem tomar para si sua história" (p. 34). Apesar de sua preocupação e do caráter militante de sua obra, estudos feministas ocorriam concomitantemente à produção do filósofo; com todo respeito à autora e à contribuição de Foucault para repensar os discursos de subordinação das mulheres, o termo "libertar" causa o estranhamento e o incômodo - apesar deste ter fornecido as ferramentas para reflexão, esta libertação tem sido conquistada no embate das penas, canetas e teclados, nas universidades, fábricas e ruas, a duros saques e cotidianamente.

Por fim, e mais importante, talvez, seja a definição de qual é o corpo do qual se fala. Se questionamos o universalismo que pretensamente nos inclui à humanidade - os homens, no caso -, precisamos repensar que a categoria mulher também não é universal. Com o advento dos estudos pós-coloniais, decoloniais e, principalmente, das teorias do feminismo interseccional, é necessário pontuar: de que corpo se fala? Uma ponderação seria necessária para se explicar que, acredito, se refira ao corpo da mulher branca e ocidental.

O livro surpreende por seu denso conteúdo em um número tão pequeno de páginas - e tudo em uma linguagem bastante acessível e de leitura prazerosa. Faz-nos refletir sobre a história enquanto construção, sobre a pretensão de universalidade da história e seu sujeito universal, sobre o corpo feminino enquanto construção histórica, filosófica, jurídica, psiquiátrica, etc. Deixa ainda a provocação: o que faremos nós, mulheres, historiadoras, para desconstruir discursos que atravessam os tempos? 
Recebido em 09/08/2016 Aprovado em 30/08/2016

Universidade do Estado de Santa Catarina - UDESC

Programa de Pós-Graduação em História - PPGH

Revista Tempo e Argumento Volume 08 - Número 18 - Ano 2016 tempoeargumento@gmail.com 